\title{
Developing Endocrinology Services in the Peripheries, a need of current times....
}

\author{
Muditha Weerakkody ${ }^{1}$, Dharshini Karuppiah ${ }^{2}$ \\ ${ }^{1}$ Diabetes and Endocrinology unit, Teaching Hospital Karapitiya \\ 2Diabetes and Endocrinology unit, Teaching Hospital Batticaloa
}

Endocrinology has come a long way in Sri Lanka, from its inception as a society in 1979, by the renowned academic in physiology, Professor Carlo Fonseka, to its current status where both the services which we offer and the academic activities which we implement are widespread throughout the country. However, as the number of doctors specialized in the field increase, one main concern is the hurdles that appear when trying to expand the services to every nook and corner of the island. Furthermore, there is the concept of establishing centers of excellence, with a number of specialists working in one unit and providing services across the genre as opposed to establishing peripherally placed units led by one specialist where basic services can be provided and patients referred to specialist units for further care. Both concepts have their advantages and disadvantages.

The story of Ms S, an actual patient from the Southern part of Sri Lanka, would highlight the issues currently faced by most patients with uncommon diseases in Sri Lanka. This 32-year-old lady, from a remote village 100 kilometers away from Galle, was first investigated for Cushing's syndrome in 2012. At that time, the only center for Endocrinology in Southern Province was in Galle, resulting in her commuting almost every week, for 3 to 4 hours each way, for investigations and treatment. Unfortunately, as it is the case in most patients with Cushing's syndrome, the aetiology could not be elicited. The next investigation of choice was inferior petrosal venous sinus sampling, which necessitated for her to be referred to National Hospital of Sri Lanka, as Galle did not have the facility at that time. Ms S, who found it extremely difficult to go to Colombo due to her social circumstances, withdrew totally from medical care. Five years later in 2017, she was referred back to Galle by a peripheral physician, this time with features of full blown Cushing's syndrome. She now showed evidence of a pituitary tumour on imaging, and also has diabetes, hypertension and dislipidaemia complicating the illness. Unfortunately, she developed a respiratory infection and went into septicaemia, and passed away two weeks later, after a prolonged stay in the intensive care unit. It was later revealed that in the meantime, the patient had resorted alternative form medical treatment, which was available to her nearer to her home. One wonders if her story would have been different, if she had an Endocrine center closer to her home, where she would have been regularly followed up, and if inferior petrosal venous sampling was available in Galle.

Establishing peripheral endocrine units, at least one per district to cover the 25 districts in the country, would be an answer to some of the difficulties faced by patients today. These centers would function as endocrine referral centers for the district and would also pioneer in establishing well equipped multi-disciplinary diabetes clinics for the district. There is an argument that these centers would not have adequate Endocrine patients and would only be catering to the diabetic population. However, if the larger referral centers delegate the follow-up of complex endocrine patients who were previously seen by them to these peripheral units, and see them only in an as required basis, the arrangement would benefit both kinds of centers longterm. The unavailability of expensive endocrine investigations would be another challenge faced by these remotely placed establishments. However, liaison with the centrally placed chemical pathology laboratories, where a quota of the laboratory investigations per month are allocated to these units, would help to circumvent this issue.

Developing centers of excellence in Endocrinology, one per province to span the nine provinces of Sri Lanka, would be the other end of the spectrum. These centers would ideally be manned by more than one endocrinologist, and would have the support of a well-equipped chemical laboratory service, have facilities for sophisticated radiological investigation facilities and would have the support of surgical expertise. They would also function as training centers for both postgraduate and undergraduate 
students. Establishment of a transfer system where there are temporary posts in these centers, in addition to the permanent non-transferable posts, will ensure that even the young Endocrinologists would have opportunities to work in these centers for pre-determined periods of times.
Provision of a comprehensive endocrine service to the people of Sri Lanka, the ambition and the vision of our college, would only become a reality if strategies such as above are implemented. 